\title{
Laser Hardening of the Functional Surfaces of Machine Tools
}

Karel Šramhauser, Sylvia Kuśmierczak

Faculty of Production Technology and Management, University of J. E. Purkyně in Usti nad Labem, Czech Republic.E-mail: editors@fvtm.ujep.cz, sramhauser@fvtm.ujep.cz, kusmierczak@fvtm.ujep.cz

The purpose of using modern technology is to reduce costs, facilitate the work and simplify as far as the most comprehensive set of operations. One of many modern technological processes involved in the refining of materials are technologies of surface hardening using a laser beam. This method can harden precisely defined areas with minimal thermal influence of surrounding areas it is possible to achieve less residual stress and less distortion of components compared the volumetric hardening, it is also possible to use controlled robotic units and all for the absence of cooling, which proceeds spontaneously to the surrounding material itself and atmosphere. These advantages of laser surface hardening are used by companies for which the prospect of minor damage to the material, increase of the material durability, material stiffness ensuring etc. is initiation for the use of modern technology.

Keywords: laser hardening, cast iron, hardness, microstructure

\section{References}

[1] PLUHǍ̆, J., KORITTA, J. (1977). Strojírenské materiály. Vyd. 2., přeprac. Praha: SNTL, 562 s. Redakce báňské a strojírenské literatury. ISBN 04-212-77.

[2] HRABĚ, P., CHOTĚBORSKÝ, R. (2005). Zvyšování životnosti abrazivně opotřebených strojních částí. MM Prưmyslové spektrum. Praha: Vogel Publishing, 18. 5. roč. 2005, č. 5.

[3] SCHUBERT, S. (2011). Kalení laserem urychluje výrobu součástí a nástrojů. MM Průmyslové spektrum [online]. Praha: Vogel Publishing, č. 7 [cit. 2015-05-03]. Dostupné z: http://www.mmspektrum.com/clanek/kaleni-laserem-urychluje-vyrobu-soucasti-a-nastroju.html

[4] Laserové kalení. VÚTS Liberec [online]. 2013 [cit. 2015-05-03]. Dostupné z: http://www.vuts.cz/laserove-kaleni-2.html

[5] ZATLOUKAL, P. (2007). Tepelné zpracování laserem. Welding.cz [online].[cit. 2015-05-03]. Dostupné z: http://www.welding.cz/laser/tepelne.htm

[6] Schématické zobrazení laserového kalení. 2015. KULIČKOVÉ ŠROUBY KUŘIM, a.s. [online]. [cit. 2015-05-09]. Dostupné z: http://www.ks-kurim.cz/laserove-kaleni/

[7] Legovaná nástrojová ocel pro práci za studena a na pružiny 102Cr6. ING. FÜRBACHER. M-Busch [online]. 2008, 3. 5. [cit. 2015-01-01]. Dostupné z: http://www.techportal.cz/33/legovana-nastrojova-ocel-pro-praci-za studena-a-na-pruziny-102cr6-uniqueidmRRWSbk196FNf8-jVUh4Eo

VtBWjC68CLJHLE75AcqcMO6VlftQMFg/?sekce=34

[8] ZETEK, M., ČESÁKOVÁ, I., SAMCOVÁ, M., SOUKUP, O. (2011). Obrábění tepelně zpracovaných ploch laserem. Strojírenská technologie. XVI(5): 49-53. ISSN 1211-4162).

[9] LUCEFIN GROUP. Technical card. Gruppo Lucefin [online]. 2011 [cit. 2015-03-31]. Dostupné http://www.lucefin.com/wp-content/files_mf/1.2067102cr6ing.pdf

[10] Materiálový list jakosti Unibar 250: Kontinuálně litý litinový profil. UCB Technometal [online]. 2013, 1. 7. [cit. 2015-01-01]. Dostupné z: http://www.ucbtechnometal.cz/storage/get/143-unibar-250-cz.pdf

[11]KŘKIǏZ̆, A. (2004). METAL 2004: 13. mezinárodní konference metalurgie a materiáli̊ : sborník préednášek = 13th international metallurgical. Vyd. 1. Ostrava: Tanger, 91 s. ISBN 80-859-8895-X.

[12] G 99 - 034. Standard Test Method for Wear Testing with a Pin-on-Disk Apparatus. 2014. West Conshohocken Spojené státy Americké): ASTM International.

Paper number: M201651

Copyright (C) 2016. Published by Manufacturing Technology. All rights reserved. 